\title{
Effect of hydraulic parameters on the computed serviceability of infrastructure slopes
}

\author{
Aikaterini Tsiampousi, Lidija Zdravkovic, and David M. Potts \\ Imperial College London, Department of Civil and Environmental Engineering, UK
}

\begin{abstract}
Atmospheric phenomena such as rainfall and evapotranspiration contribute to slope movements in unsaturated soils, the study of which requires fully coupled numerical methods, combined with realistic boundary conditions and appropriate mechanical and hydraulic soil properties. This paper focuses on the effect of the hydraulic behaviour, and in particular of the modelling of the soil-water retention curve and the permeability on slope movements, with the aim of identifying which model parameters are critical and, therefore, require careful experimental identification.
\end{abstract}

\section{Introduction}

Seasonal changes of rainfall and evapotranspiration rates cause swelling of soil during the wetter, winter months and shrinkage during the drier, summer months. In infrastructure slopes an accumulation of shrinkage with time has been observed [1], causing serviceability and stability problems [2-4]. Although the effect of the mechanical parameters, i.e. parameters controlling the strength and stiffness of soils, on the stability and serviceability of slopes is relatively well understood, the effect of hydraulic parameters controlling the soil-water retention curve (SWRC) and the permeability of the soil is less clear and has not been comprehensively studied.

This paper studies the numerical reproduction of the cyclic alteration between swelling and shrinkage and accumulation of shrinkage with time, when different SWRC and permeability models and parameters are employed in the analysis. The aim of the study was to identify the critical parameters and modelling decisions which often need to be made in the absence of conclusive laboratory data and, therefore, to provide a means of devising an experimental programme which prioritises aspects of the hydraulic soil behaviour shown to have the greatest impact on the numerical analysis, over aspects that, although important in the modelling and understanding of soil behaviour, may result in a marginal overall impact on geotechnical applications. To this end, an excavated slope in an unsaturated silty soil of low swelling potential was considered in a series of parametric Finite Element (FE) analyses performed with ICFEP [5]. To aid the discussion, the SWR and permeability models used are summarised first, placing emphasis on the parameters varied in the study, and the boundary value problem and the analysis results are presented and discussed next.

Corresponding author: aikaterini.tsiampousi@imperial.ac.uk

\section{Hydraulic modelling}

\subsection{Monotonic SWR model}

The monotonic SWR model used in the analyses is an extension of the van Genuchten [6] model by Melgarejo [7], expressed by the following equation:

$$
S_{r}=\left\{\frac{1}{1+\left[\alpha\left(s-s_{\text {air }}\right)\right]^{n}}\right\}^{m}\left(1-S_{r, 0}\right)+S_{r, 0}
$$

where $S_{r, 0}$ is the residual degree of saturation, $S_{r} ; s_{\text {air }}$ is the air-entry value of suction, $s$; and $\alpha, n$ and $m$ are fitting parameters.

\subsection{Monotonic, specific volume-dependent SWR model (3D monotonic SWR model)}

The monotonic, specific volume-dependent SWR model used in the analyses is an extension of the Gallipoli et al. [8] model by Tsiampousi [9], expressed by the following equation:

$$
S_{r}=\left\{\frac{1}{1+\left[\alpha(v-1)^{\psi}\left(s-s_{\text {air }}\right)^{n}\right]}\right\}^{m}\left(1-S_{r, 0}\right)+S_{r, 0}
$$

where $v$ is the specific volume; $S_{r, 0}$ is the residual degree of saturation, $S_{r} ; s_{a i r}$ is the air-entry value of suction, $s$; and $\alpha, n$ and $m$ are fitting parameters. Parameter $\psi$ controls the effect of the specific volume, as explained below.

By including the specific volume, $v$, in Equation 2, the SWRC becomes a surface (SWRS) in the $s-S_{r}-v$ space, 
as illustrated in Figure 1a. Also shown in the same figure are hypothetical retention curves followed under constant specific volume which are referred as iso-volumetric SWRCs [10]. Projecting the iso-volumetric curves onto the $\mathrm{s}-S_{r}$ plane, the image illustrated in Figure $1 \mathrm{~b}$ is obtained. Evidently, the position of the retention curve is moved upwards or downwards depending on whether the specific volume is decreasing or increasing, respectively. However, it is highly improbable that unsaturated soils maintain their volume unaffected during mechanical loading (i.e. changes in applied stress) or hydraulic loading (i.e. changes in applied suction). Gradual changes of the specific volume impose a continuous shift of the retention relationship from one iso-volumetric curve to the next one and the retention point, defined in the $s-S_{r}$ $v$ space, moves on the 3D SWRS. The distance between the iso-volumetric curves is controlled by the model parameter $\psi$ and is expected to be less pronounced for decreasing values of this parameter, while no effect is taken into account when $\psi=0 . \psi$ cannot obtain negative values.

It is not possible to measure experimentally the value of $\psi$, as the specific volume changes continuously during hydraulic loading (until a residual volume is reached). Its value can only be inferred from high quality experimental data where the volume changes of the soil samples have been recorded carefully during drying and wetting. Ideally, SWRC should be measured at different initial specific volumes, but even then determination of the value of $\psi$ is not easy and relies heavily on the judgment of the model user.

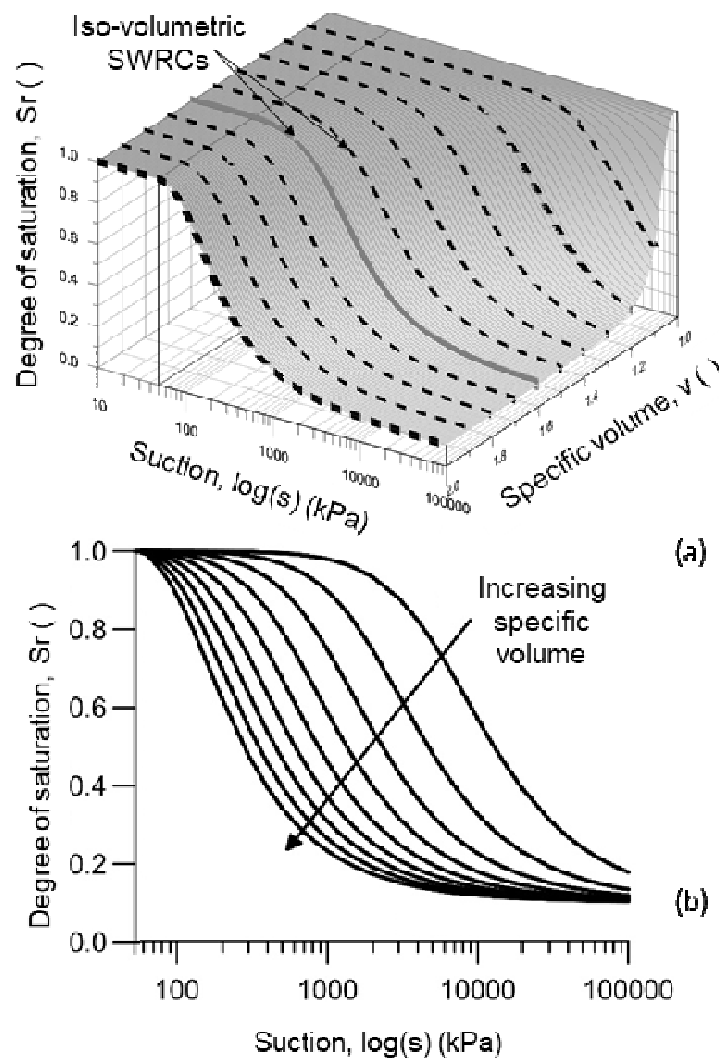

Fig. 1. Iso-volumetric SWRCs (a) in the 3D $s-S_{r}-v$ space and (b) projected onto the $s-S_{r}$ plane.

\subsection{Hysteretic SWR model}

The hysteretic SWR model of Tsiampousi [9], which was used in the analyses, employed the following equation to calculate the degree of saturation on the primary drying $\left(S_{r, p r}^{d r}\right)$ and primary wetting $\left(S_{r, p r}^{\text {wet }}\right)$ curves:

$$
S_{r, p r}^{d r, w e t}=\frac{1-\frac{1}{s_{0, e q}} \cdot s_{e q}}{1+\alpha_{d, w} \cdot s_{e q}}
$$

where $s_{e q}=s-s_{\text {air }}$ is the equivalent suction, $s_{\text {air }}$ being the air-entry value of suction and s being the current value of suction. Equally, $s_{0, e q}=s_{0}-s_{\text {air }}$, where $s_{0}$ is the value of suction at which the residual degree of saturation (assumed zero for simplicity) is reached. $\alpha$ is a fitting parameter, carrying the index $d$ for drying and $w$ for wetting. For the wetting path to lie beneath the drying path, $\alpha_{w}$ has to be larger than $\alpha_{d}$, while if they are equal a monotonic curve is generated.

On drying from an initial retention point $\mathrm{A}$, defined in the $s-S_{r}$ plane by its co-ordinates $\left(s_{A}, S_{r, A}\right)$ and positioned in between the two primary curves, the soil is assumed to follow the scanning path $\mathrm{AB}^{\mathrm{dr}}$ shown in Figure $2 \mathrm{a}$. This scanning path is assumed to be the arc of a circle, centred on the vertical line passing through point $\mathrm{A}$ so that the suction corresponding to the centre of the circle is equal to the suction at point $\mathrm{A}, s_{A}$. The circle and the primary drying curve have a common tangent at point $\mathrm{B}^{\mathrm{dr}}\left(s_{B}^{d r}\right.$, $S_{r, B}^{d r}$ ), also shown in Figure 2a. In this way, the slope of the scanning path is always zero at point $\mathrm{A}$ and a smooth transition from the scanning to the primary drying path is provided at point $\mathrm{B}^{\mathrm{dr}}$. The radius of the circle, $\mathrm{r}_{\mathrm{dr}}$, and the suction at point $\mathrm{B}^{\mathrm{dr}}, s_{B}^{d r}$, are identified numerically and substituted into the equation for the scanning drying curve:

$$
S_{r, s c a n}^{d r}=S_{r, A}-r_{d r}+\sqrt{\left[r_{d r}^{2}-\left(\log s_{e q}-\log s_{A}\right)^{2}\right]}
$$

Equally, on wetting from point A, the scanning path $\mathrm{AB}^{\text {wet }}$ is the arc of a circle with equivalent restrictions. The equation for the scanning wetting path is:

$$
S_{r, s c a n}^{w e t}=S_{r, A}+r_{w e t}-\sqrt{\left[r_{w e t}^{2}-\left(\log s_{A}-\log s_{e q}\right)^{2}\right]}
$$

where $r_{w e t}$ is the radius of the circle on wetting.

The model is used in combination with the following equation describing the relationship between the degree of saturation $\mathrm{Sr}$ and the coefficient of compressibility with suction, $\kappa_{s}$ :

$$
\kappa_{s}=\chi \cdot\left(S_{r}\right)^{\omega}
$$

where $\chi$ and $\omega(\omega \geq 0)$ are fitting parameters. When $\omega=0$ the coefficient $\kappa_{s}$ is independent of the degree of saturation and equal to $\chi$. Also, when $S_{r}$ is equal to $1, \kappa_{s} \approx \chi$ and therefore the value of $\chi$ should resemble the value of the elastic coefficient of volume change $\kappa$. 
The determination of parameters $\chi$ and $\omega$ is not as challenging as the determination of $\psi$. It relies on the availability of good quality data of specific volume versus suction and requires the usual level of judgment applied to any curve fitting exercise.

\subsection{Hysteretic, specific volume-dependent SWR model (3D hysteretic SWR model)}

The hysteretic, specific volume-dependent SWR model used in the analysis is an extension by Tsiampousi et al. [10] of the Tsiampousi [9] model above, and is based on the same assumptions regarding the primary and scanning paths. To account for the effect of specific volume, the model employs the notion of combined suction:

$$
s_{\text {eq }}^{*}=(v-1)^{\psi} \cdot\left(s-s_{\text {air }}\right)
$$

where parameter $\psi$ controls the effect of specific volume $v$ in the same way as in the Gallipoli et al. [8] model. Instead of Equation 3, the following expression is used for the primary paths:

$$
S_{r, p r}^{d r, w e t}=\frac{1-\frac{1}{s_{0, e q}} \cdot s_{e q}^{*}}{1+\alpha_{d, w} \cdot s_{e q}^{*}}
$$

Introducing the notion of combined suction enables the representation of the 3-dimentional retention curve defined in the $s-S_{r}-v$ space on the 2-dimentional $s_{e q}^{*}-S_{r}$ plane, as shown on Figure $2 b$.

\subsection{Suction-dependent permeability model}

The main assumption of the model [5] is that the logarithm of permeability varies linearly with suction from its initial value $k_{s a t}$, corresponding to suction $s_{l}$, to a limiting value $k_{\min }$, corresponding to suction $s_{2}$. The magnitude of permeability corresponding to the current suction level, $s$, can, therefore, be obtained from the following equation:

$$
\log k=\log k_{\text {sat }}-\frac{s-s_{1}}{s_{2}-s_{1}} \log \left(\frac{k_{\text {sat }}}{k_{\text {min }}}\right)
$$

For values of suction smaller than $s_{I}$ the permeability is equal to $k_{\text {sat }}$, whereas for suction levels higher than $s_{2}$ the permeability is equal to $k_{\min }$.

\subsection{Degree of saturation-dependent permeability model}

Equation 9 is thought to be adequate only when monotonic changes of suction are applied or for soils exhibiting insignificant hydraulic hysteresis, as a hysteretic relationship between permeability and suction is believed to exist, similarly to the retention behaviour [12]. However, the permeability-water content or degree of saturation relationship shows essentially no hysteresis, as discussed by Fredlund \& Rahardjo [13], and therefore, the following expression should preferably be employed when cyclic changes of suction are expected:

$$
k=k_{s a t} \cdot \frac{s_{r}-s_{r 0}^{1 / 2}}{1-s_{r 0}} \cdot\left[1-\left(1-\frac{s_{r}-s_{r 0}^{1 / m}}{1-s_{r 0}}\right)^{m}\right]^{2}
$$

$S_{r 0}$ being the residual degree of saturation and $m$ a fitting parameter [6].

As Equation 10 increases the computational cost of the analysis, especially when used in conjunction with the 3D hysteretic SWR model, it was only employed in one of the analyses, as explained below, to investigate whether it bears significant impact on the computed results.

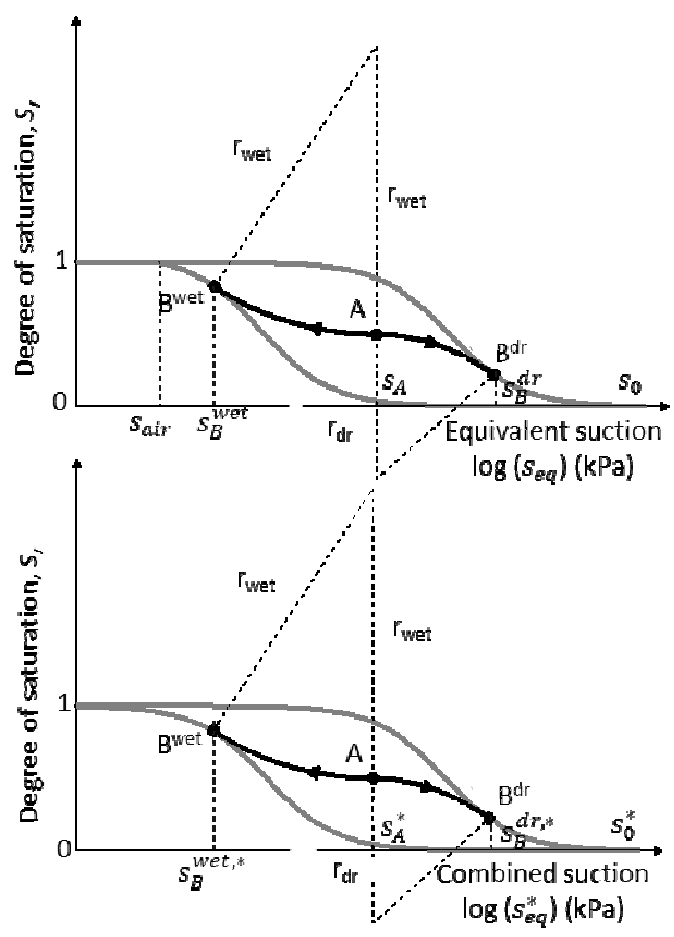

Fig. 2. Primary and scanning drying and wetting paths assumed in the model of (a) Tsiampousi [9] and (b) Tsiampousi et al. [10].

\section{Problem description}

A $10 \mathrm{~m}$ deep excavation with the geometry shown in Figure $3 \mathrm{a}$ was considered in plane strain. The corresponding mesh, consisting of quadrilateral isoparametric 8-noded elements is shown in Figure 3b.

The stresses were initialised assuming a unit weight of $19.1 \mathrm{kN} / \mathrm{m}^{3}$, a coefficient of earth pressures at rest, $\mathrm{K}_{0}$, of 1 and hydrostatic pore water pressures (pwp) above (suctions) and below the ground water table (GWT), which was $5 \mathrm{~m}$ deep. The excavation was performed in 20 stages of the coupled consolidation analysis, removing $0.5 \mathrm{~m}$ of soil at each stage, in a total of 15 days. Following the excavation, 5 years of soil-atmosphere interaction were simulated, as explained below, using rainfall and evapotranspiration data from the Building Research Establishment testing site at Chattended, Kent, UK, 
referring to years 1970 to 1974 . The atmospheric data were applied on a monthly basis and each moth was simulated over 12 increments of the coupled consolidation analysis.

The horizontal displacements at the axis of symmetry and the right-hand-side vertical boundary, and the horizontal and vertical displacements at the bottom of the mesh were set to zero. The axis of symmetry and the bottom boundary were impermeable throughout the analysis. During the excavation, the pore water pressures at the right-hand-side vertical boundary were not allowed to change. This boundary was considered impermeable during the stages of the analysis simulating soilatmosphere interaction so that that water flow was only possible in the vertical direction under the effect of rainfall and evapotranspiration. During the excavation, the precipitation boundary condition [14] was applied to the sloping boundary underneath the initial GWT and the bottom boundary of the excavation, allowing conditions to change automatically from an impermeable boundary to a zero prescribed pwp. The precipitation boundary condition was also used to simulate the effect of rainfall on the initial horizontal ground behind the excavation and on the sloping boundary, allowing conditions to change automatically from a prescribed flow rate, inferred from the rainfall data, to $10 \mathrm{kPa}$ of suction [3]. The evapotranspiration boundary condition of Nyambayo \& Potts [15] was prescribed simultaneously on the same nodes to simulate the effect of vegetation.

The mechanical behaviour of the silty soil considered was simulated with an extension of the Barcelona Basic Model (BBM, [16]) by Georgiadis et al. [17] and Tsiampousi et al. [11]. The values of the corresponding model parameters were defined by Tsiampousi et al. [11] based on experimental data by Estabragh \& Javadi [18].
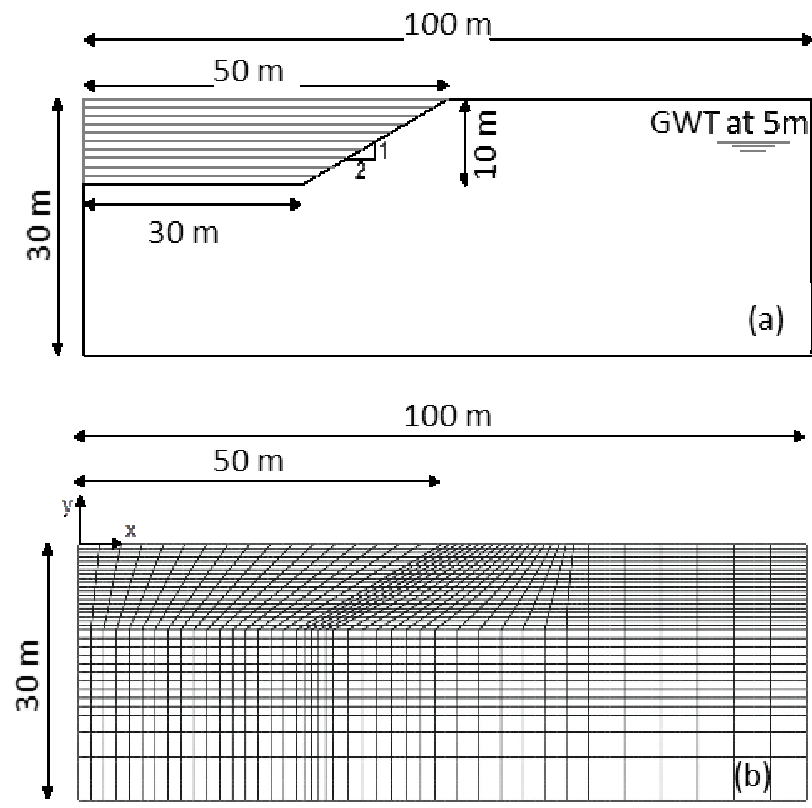

Fig. 3. (a) Excavation geometry; (b) finite element mesh.

Of the eleven analyses summarised in Table 1, ten adopted the suction-dependent and one (D.1.perm) the degree of saturation-dependent permeability model. One analysis (A) adopted the monotonic SWRC model. The results of analysis A can be compared those of analyses B.1, 2 and 3, which adopted the 3D monotonic SWRC model with different values of the parameter $\psi$, to study the effect of this parameter when a monotonic SWRC is used. Three analyses (C.1, 2 and 3) were performed with the hysteretic SWRC and different values for parameter $\omega$, and three (D.1, 2 and 3) with the 3D hysteretic SWRC model with different values for parameter $\psi$ and a value for parameter $\omega$ which makes them comparable to analysis C.2. Of the latter three analyses, D.1 is directly comparable to D.1.perm allowing the effect of permeability model to be studied. The SWRC models and parameters employed in each analysis are summarised in Table 1

\section{Results}

The horizontal and vertical displacements of the top of the slope are presented in Figure 4 for all analyses. Positive horizontal and negative vertical displacements signify shrinkage whereas negative horizontal and positive vertical displacements are associated with swelling. The vertical displacements in analysis A (Fig. 4a) demonstrate swelling during the wetter, winter months and shrinkage during the drier, summer months. Nonetheless, the horizontal displacements exhibit progressively increasing shrinkage with time and swelling is almost absent. The monotonic SWR model cannot capture qualitatively the expected alteration of shrinkage and swelling between summer and winter. With reference to analyses B.1, 2 and 3 in the same figure, it can be observed that the 3D monotonic SWR model was capable of reproducing the expected behaviour only when a large value of $\psi(=5)$ was adopted in the analysis. However, the specific volume is not expected to change significantly with suction in a soil of low swelling potential like the silty soil considered here and, therefore, its effect on the retention curve is not expected to be large. Consequently, it is doubtful that such large values of $\psi$ are representative of the soil.

Figure $4 \mathrm{~b}$ compares the displacements computed with the monotonic and the hysteretic SWRC models for different values of parameter $\omega$. All analyses captured the change of behaviour from shrinkage to swelling as evident from both the horizontal and the vertical displacements, independently of the value of parameter $\omega$. The largest displacements were calculated for $\omega=0$, where the coefficient of compressibility with suction, $\kappa_{s}$, is constant and independent of the degree of saturation. This is reasonable, as larger values of $\omega$ lead to smaller values of $\kappa_{s}$ and, therefore, smaller displacements due to suction changes.

The results for the analyses employing the 3D hysteretic SWRC model are shown in Figure 4c. The change from shrinkage to swelling is clearly visible in all analyses. Interestingly, the analyses with $\psi$ equal to 0 and to 1 almost coincide and show little difference compared to the displacements for $\psi=2$. Noticeable difference is marked only when $\psi=3$.

Finally, Figure $4 \mathrm{~d}$ shows the results of the analyses performed with different permeability models. Due to the 
computational cost for the analysis with the degree of saturation-dependent permeability model, only two instead of five years of soil-atmosphere interaction were simulated. The difference between the results obtained with the two models are only minor, meaning that the simpler suction-dependent model may be adopted with no significant impact on the analysis results.

\section{Conclusions}

The analyses presented refer to a silty, reasonably permeable soil with low swelling potential. It can be concluded from the results that only the hysteretic SWR model was capable of reproducing the expected change of movements from shrinkage to swelling under seasonal changes of suction, independently of parameter $\psi$. Nonrealistic values of this parameters had to be adopted in the 3D monotonic SWRC model in order to obtain the expected behaviour. Although the value of parameter $\omega$ did not affect the results in a qualitative manner, it certainly affected the magnitude of displacements and its laboratory determination appears to be of value. Contrary, the magnitude of parameter $\psi$, when within limits representative of the soil examined, appeared to have a smaller effect on the analysis results. As its experimental determination is not straightforward but relies heavily on the interpretation of the laboratory data, and therefore, on the judgment of the user calibrating the SWR model, an approximate determination may be adequate. Finally, permeability can be considered a function of suction rather than of the degree of saturation, rendering the analysis more cost effective, with little impact on the computed displacements.

\section{References}

1. A.S. O'Brien, E.A. Ellis, D. Russell, Proc. Adv. Geot. Eng., The Skempton Conf., Thomas Telford, London, Pages: 911-921, (2004).

2. N. Kovacevic, D.M. Potts, P.R. Vaughan, Proc. Int. Conf. Soil Mech. Geot. Eng. AA BALKEMA PUBLISHERS, 3, Pages: 2127-2130 (2001).
3. A. Tsiampousi, L. Zdravkovic L. D.M. Potts,3rd Eur. Conf. Unsat. Soils, Publisher: EDP Sciences, ISSN: 2267-1242 (2016).

4. A. Tsiampousi, L. Zdravkovic L. D.M. Potts, Can. Geot. J., 54 (3), Pages: 405-418 (2016).

5. D.M. Potts, L. Zdravkovic, Finite element analysis in geotechnical engineering: Theory. London, Thomas Telford (1999).

6. M.T. van Genuchten, Soil Science Soc. Am. J., 44 (5), Pages: 892-899 (1980).

7. M.L.C. Melgarejo, Laboratory and numerical investigations of soil-water retention curves $\mathrm{PhD}$ Thesis. Imperial College, University of London, UK (2004).

8. D. Gallipoli, S.J. Wheeler, M. Karstunen, Géotechnique, 53 (1), Pages: 105-112 (2003).

9. A. Tsiampousi, Numerical analyses of slopes in unsaturated soils, $\mathrm{PhD}$ thesis, Imperial College London, UK (2011).

10. A. Tsiampousi, L. Zdravkovic, D.M. Potts, Géotechnique, 63 (2), Pages: 155-164 (2013).

11. A. Tsiampousi, L. Zdravkovic, D.M. Potts, Comp. and Geot., 48, Pages: 156-166 (2013).

12. A.C. Liakopoulos, Bull. Int. Assoc. Sci. Hydrol., 10, 5-39 (1965).

13. D.G. Fredlund, H. Rahardjo, Soil mechanics for unsaturated soils, Wiley Interscience Publication (1993)

14. P.G.C. Smith, D.M. Potts, T.I. Addenbrook, 1st Eur. Conf. Unsat. Soils, Durham, UK, Pages: 773-778 (2008).

15. V.P. Nyambayo, D.M Potts, Comp. and Geot. 37, Pages: 175-186 (2010).

16. E.E. Alonso, A. Gens, A. Josa, Géotechnique, 40 (3), 405-430 (1990)

17. K. Georgiadis, D.M. Potts, L. Zdravkovic, Int. J. Geom., 5 (3), Pages: 244-255 (2005).

18. A.R. Estabragh, A.A. Javadi, Can. Geot. J., 45 (3), 408-420 (2008).

Table 1. SWRC and permeability model and values of model parameters adopted in parametric analyses.

\begin{tabular}{|c|c|c|c|c|c|c|c|c|c|c|c|c|c|c|}
\hline $\begin{array}{c}\text { Analysis } \\
\text { Name }\end{array}$ & SWRC Model & $\begin{array}{c}\alpha \\
1 / \mathrm{kPa}\end{array}$ & $\begin{array}{l}n \\
-\end{array}$ & $\begin{array}{c}m \\
-\end{array}$ & $\begin{array}{c}S_{r, 0} \\
\%\end{array}$ & $\psi$ & $\begin{array}{l}\omega \\
-\end{array}$ & Permeability Model & $\begin{array}{l}k_{\text {sat }} \\
\mathrm{m} / \mathrm{s}\end{array}$ & $\begin{array}{c}s_{1} \\
\mathrm{kPa}\end{array}$ & $\begin{array}{c}s_{2} \\
\mathrm{kPa}\end{array}$ & $\begin{array}{c}K_{\min } \\
\mathrm{m} / \mathrm{s}\end{array}$ & $\begin{array}{l}S_{r 0} \\
\%\end{array}$ & $\begin{array}{r}m \\
-\end{array}$ \\
\hline A & Monotonic & 0.015 & 0.95 & 0.7 & 10 & - & - & Suction-dependent & $10^{-8}$ & 0 & $10^{3}$ & $10^{-10}$ & - & - \\
\hline B.1 & 3D Monotonic & 0.015 & 0.95 & 0.7 & 10 & 1 & - & Suction-dependent & $10^{-8}$ & 0 & $10^{3}$ & $10^{-10}$ & - & - \\
\hline B. 2 & 3D Monotonic & 0.015 & 0.95 & 0.7 & 10 & 2 & - & Suction-dependent & $10^{-8}$ & 0 & $10^{3}$ & $10^{-10}$ & - & - \\
\hline \multirow[t]{2}{*}{ B.3 } & 3D Monotonic & 0.015 & 0.95 & 0.7 & 10 & 5 & - & Suction-dependent & $10^{-8}$ & 0 & $10^{3}$ & $10^{-10}$ & - & - \\
\hline & & $\begin{array}{l}\alpha_{d} \\
(-)\end{array}$ & $\begin{array}{l}\alpha_{w} \\
(-)\end{array}$ & $\begin{array}{c}S_{\text {air }} \\
(\mathrm{kPa})\end{array}$ & $\begin{array}{c}s_{0} \\
(\mathrm{kPa})\end{array}$ & $\psi$ & $\omega$ & & $\begin{array}{l}k_{\text {sat }} \\
\mathrm{m} / \mathrm{s}\end{array}$ & $\begin{array}{c}s_{1} \\
\mathrm{kPa}\end{array}$ & $\begin{array}{c}s_{2} \\
\mathrm{kPa}\end{array}$ & $\begin{array}{c}K_{\min } \\
\mathrm{m} / \mathrm{s}\end{array}$ & $\begin{array}{c}S_{r 0} \\
\%\end{array}$ & $\begin{array}{r}m \\
-\end{array}$ \\
\hline C.1 & Hysteretic & 0.008 & 0.05 & 0 & $10^{5}$ & - & 0 & Suction-dependent & $10^{-8}$ & 0 & $10^{3}$ & $10^{-10}$ & - & - \\
\hline C. 2 & Hysteretic & 0.008 & 0.05 & 0 & $10^{5}$ & - & 2 & Suction-dependent & $10^{-8}$ & 0 & $10^{3}$ & $10^{-10}$ & - & - \\
\hline C. 3 & Hysteretic & 0.008 & 0.05 & 0 & $10^{5}$ & - & 4 & Suction-dependent & $10^{-8}$ & 0 & $10^{3}$ & $10^{-10}$ & - & - \\
\hline D.1 & 3D Hysteretic & 0.008 & 0.05 & 0 & $10^{5}$ & 1 & 2 & Suction-dependent & $10^{-8}$ & 0 & $10^{3}$ & $10^{-10}$ & - & - \\
\hline D. 2 & 3D Hysteretic & 0.008 & 0.05 & 0 & $10^{5}$ & 2 & 2 & Suction-dependent & $10^{-8}$ & 0 & $10^{3}$ & $10^{-10}$ & - & - \\
\hline D. 3 & 3D Hysteretic & 0.008 & 0.05 & 0 & $10^{5}$ & 3 & 2 & Suction-dependent & $10^{-8}$ & 0 & $10^{3}$ & $10^{-10}$ & - & - \\
\hline D.1.perm & 3D Hysteretic & 0.008 & 0.05 & 0 & $10^{5}$ & 1 & 2 & Degree of sat.-dep. & $10^{-8}$ & - & - & - & 0 & 0.7 \\
\hline
\end{tabular}




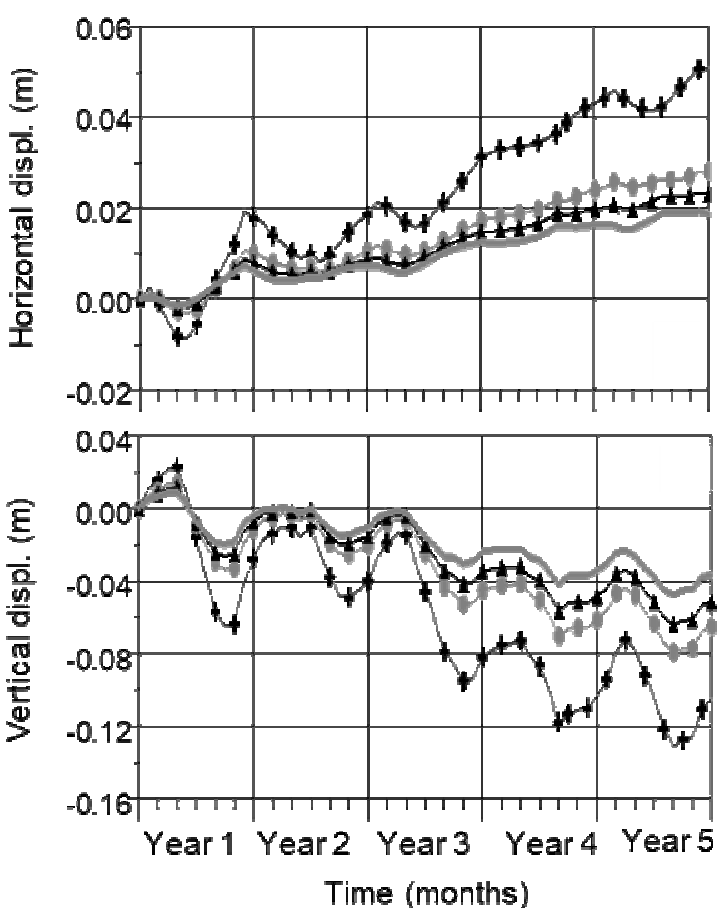

Anal. . A

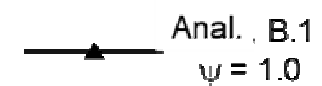

Anal. B.2

$\psi=2.0$

Anal. B.3

$\psi=5.0$
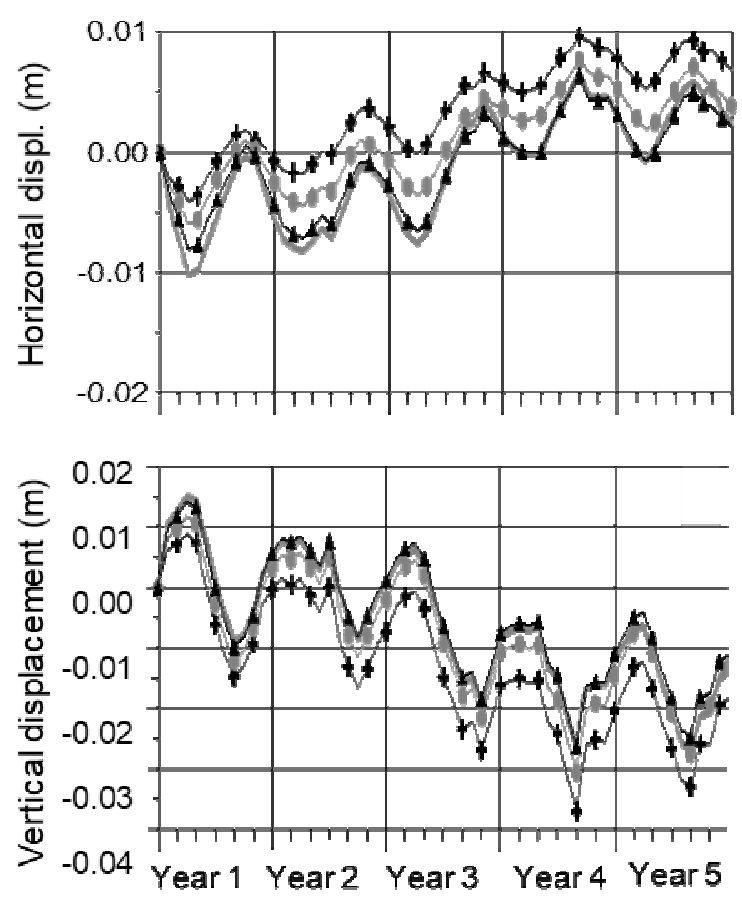

Time (months)

Anal. C.2

$\psi=0$

Anal. D.

Anal. D.2

$\psi=1$

$\psi=2$ Anal. D.3

$\psi=3$
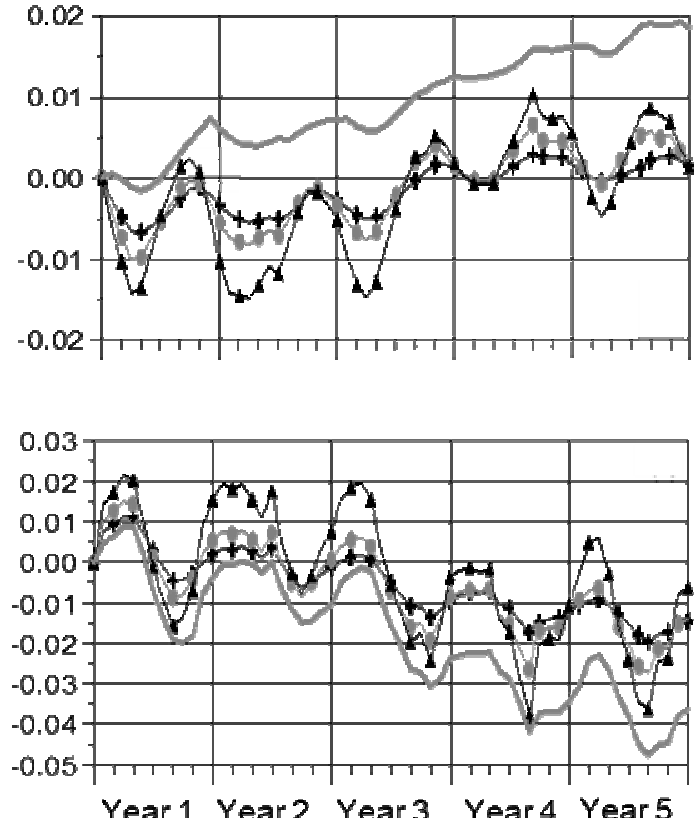

Time (months)

Anal. A

Monotonic

SWR model

Anal. C.1

Anal. C.2

Anal. C.3

$\omega=2$

$\omega=4$

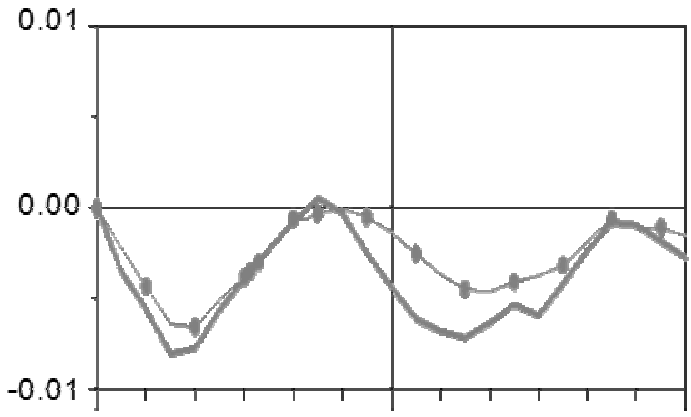

0.02

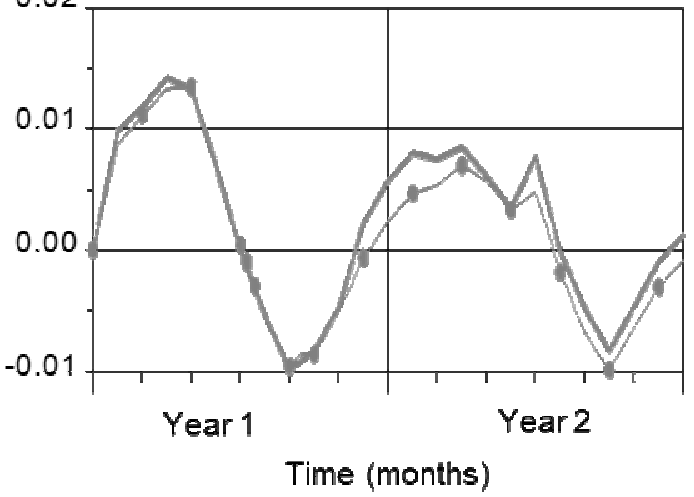

Anal. D.1

$k=f(s)$

(d)

Anal. D.1.perm

$k=f\left(S_{r}\right)$

Fig. 4. Analyses results 